\title{
Concomitant surgery for aortic valve and lung cancer patients in an elder
}

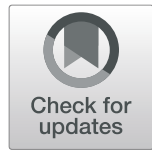

Hongfei $\mathrm{Xu}$, Tingting Tao, Liang Ma, Weidong $\mathrm{Li}^{*}$ and Yiming $\mathrm{Ni}^{*}$

\begin{abstract}
Background: The treatment strategy for aortic valve and lung cancer patients includes concomitant or two-stage procedures. Conventional simultaneous operations are usually performed under the median sternotomy.

Case presentation: A 72-year-old man was admitted to our hospital after experiencing chest tightness after activity for two months. Aortic valve regurgitation had been confirmed when squamous cell carcinoma of the lung was discovered. The therapeutic strategy for these patients is controversial. Considering the potential risk of tumour metastasis and the risk of cardiopulmonary bypass (CPB), we recommended concomitant transcatheter aortic valve implantation (TAVI) and a lobectomy. A trans-apical TAVI with left-sided intercostal thoracotomy was successfully performed, followed by an immediate video-assisted thoracoscopic surgery (VATS) lobectomy and selective lymph node dissection.
\end{abstract}

Conclusions: We suggest that a one-stage surgery of pulmonary resection following TAVI is an acceptable and safe choice after careful evaluation and should be performed as soon as possible in response to lung cancer in elderly patients with aortic valve disease.

Keyword: Transcatheter aortic valve implantation; lung cancer; concomitant surgery

\section{Background}

Lung cancer can be incidentally discovered during preoperative evaluation of aortic valve regurgitation. The treatment strategy includes concomitant or two-stage surgery. The conventional simultaneous operation for valve replacement and lung resection is usually performed under the median sternotomy. Here, we describe a way to treat both diseases through concomitant transapical TAVI and VATS lobectomy and selective lymph node dissection, avoiding the adverse effects of $\mathrm{CPB}$, repeated anaesthesia and pain without delaying lung cancer treatment.

\section{Case Presentation}

A 72-year-old male patient was admitted to our hospital. He had been experiencing chest tightness and blood in his sputum for two months. A transoesophageal ultrasound

\footnotetext{
* Correspondence: liweidong@zju.edu.cn; 1183020@zju.edu.cn Department of Cardiovascular Surgery, The First Affiliated Hospital of Zhejiang University, Number 79 Qingchun Road, Hangzhou, China
}

revealed moderate to severe aortic valve regurgitation (Fig. 1a), a result of cusp prolapse due to generalized disease, and a chest X-ray indicated lung infections (Fig. 1b). Computed tomography (CT) scans before TAVI revealed a partial blockage in the left upper lobe bronchus (Fig. 1c), and a bronchoscopic biopsy revealed left upper lobe squamous cell carcinoma (Fig. 1d). In this complex situation of senile aortic valvular disease with lung cancer, we used a concomitant trans-apical TAVI with left-sided intercostal thoracotomy and then sleeve resection of the left upper lobe and lymph node dissection by right lateral decubitus. Our apical TAVI incision was located in the left fifth intercostal space and was about $3 \mathrm{~cm}$ in size. The patient's lung cancer was located on the left side, so when we finished the TAVI, we changed the patient's position from the supine position to the right lateral decubitus position. Then we disinfected and spread the towel, used the same incision of the left fifth intercostal space as an auxiliary operation hole and added a $5 \mathrm{~cm}$ incision in the left third intercostal space as the main operation hole. We also 

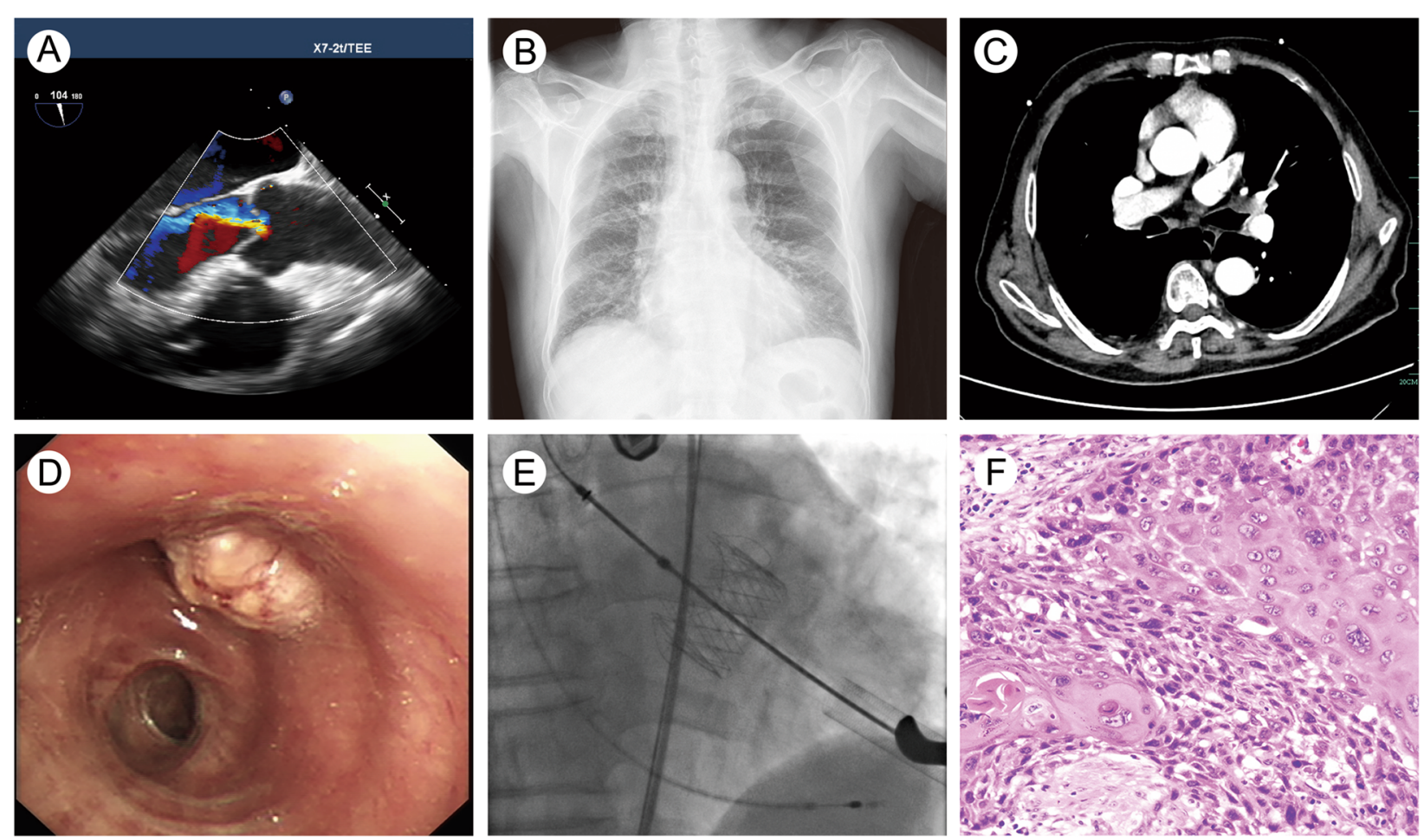

Fig. 1 a Transesophageal echocardiography showed that the aortic valve was trilobal, with poor valve closure and moderate to severe regurgitation (Vmax 4.3 m/s, LVDD 62 mm, LVEF 55\%). b The chest X-ray indicated chronic bronchitis, emphysema and two lung infections. (C) The CT scan showed a partial blockage in the left upper lobe bronchus. $\mathbf{d}$ The bronchoscope showed a tumour in the left upper lobe. The distance from the carina is more than $2 \mathrm{~cm}$, and a later biopsy revealed squamous cell carcinoma. e The intraoperative angiography showed a $29 \mathrm{~J}$-Valve was implanted from the apex of the heart. $\mathbf{f}$ The pathological findings revealed central highly differentiated squamous cell carcinoma (HE $\times 400)$

added a $1 \mathrm{~cm}$ observation hole between the seventh intercostal space to complete the sleeve resection under thoracoscopy. The operation lasted about five hours. A $29 \mathrm{~J}-$ Valve (JieCheng Medical Technologies, Suzhou, China) (Fig. 1e) was implanted, and the left upper lung lobe was excised through sleeve resection with negative margins. The tumour was $1.8 \times 1.5 \times 0.8 \mathrm{~cm}$ in size, and the bronchial wall was involved. Pathological findings revealed central highly differentiated squamous cell carcinoma (Fig. 1f) with the pathological stage of T2NOM0 stage IB. The patient recovered well after the operation. The drainage tube was removed on the fifth day, and the patient was discharged on the eleventh day. After the operation, he received radiotherapy for the left hilum and the left lung (Dt: 5000 cGy/25f, 200 cGy/f, 5f/W) 18 times. The aortic valve is normally functional with a mean gradient of $10 \mathrm{mmHg}$ at the 12-month follow-up appointment. And the lung tumour recurred.

\section{Discussion and Conclusions}

Lung cancer and severe valvular heart disease occasionally coexist. The therapeutic strategy for these patients is controversial. The incidental finding rate of lung nodules on CT scans for TAVI is about $18 \%$ [1]. There are no guidelines marking clear treatment recommendations in this situation. Undergoing cardiac surgery with CPB may cause dissemination of the coexisting lung cancer [2], and a four- to six-weeks delay could lead to unreliability or metastatic spreading. Conversely, undergoing lung surgery first will significantly increase the risks associated with anaesthesia and the risk of death [3]. The conventional simultaneous operation for valve replacement and lung resection is usually performed under the median sternotomy. Usually doctors will do valve surgery under $\mathrm{CPB}$ and then wait for protamine to antagonize heparin before performing pulmonary resection from the median incision. In addition, we know that minimally invasive valve surgery can be performed for valve diseases under $\mathrm{CPB}$ through a small right intercostal space incision. When the pulmonary nodule is located on the right lung, we can use the same incision on the right side to complete the lung surgery after the protamine injection. However, performing concomitant or twostage procedures does not avoid CPB complications, including bleeding or tumour metastasis. Thus, some surgeons report that patients with both diseases can be treated with a two-stage surgery of TAVI followed by lobectomy [4]. In the past decade, TAVI has become a 
safe alternative strategy for treating aortic valve disease [5]. Kelpis suggested that TAVI with simultaneous pulmonary resection has a good long-term result [6]. Therefore, for this patient, we believed that a transapical TAVI operation and a VATS lung cancer radical operation could be completed at the same time through one left intercostal space incision, avoiding the potential for tumor metastasis afforded by $\mathrm{CPB}$ and the time interval before lung surgery, the risk of injury due to repeated anaesthesia and the high risk of an open-heart operation.

The number of elderly patients with simultaneous aortic valve disease and lung tumours is increasing. We suggest that a one-stage surgery of pulmonary resection following TAVI is an acceptable and safe choice after careful evaluation and should be performed as soon as possible for elderly patients with lung cancer and aortic valve disease.

\section{Abbreviations}

CPB: Cardiopulmonary bypass; TAVI: Transcatheter aortic valve implantation; VATS: Video-assisted thoracoscopic Surgery; LVDd: Left ventricular diastolic diameter; CT: Computer tomography

\section{Acknowledgements}

Not applicable.

\section{Authors' contributions}

HX wrote the original manuscript.TT and LM revised the paper. YN prepared the figures and WL drafted the final manuscript. All authors read and approved the final manuscript.

\section{Funding}

This manuscript was supported by Natural Science Foundation of Zhejiang Province, Zhejiang, China, Grant /Award Number: LQ19H070002 and LGF18H020006.

\section{Availability of data and materials}

The datasets used and analyzed during the current study are available from the corresponding author on reasonable request.

\section{Ethics approval and consent to participate}

We announce that the patient involved is consent to participate, not applicable on ethics approval.

\section{Consent for publication}

We announce that all presentations of this case report have consent to publish.

\section{Competing interests}

The authors declare that they have no competing interests.

Received: 13 March 2020 Accepted: 1 September 2020

Published online: 16 September 2020

\section{References}

1. Ha FJ, Tham JLM, Paleri S, et al. Outcomes of incidental findings on multidetector computed tomography for transcatheter aortic valve implantation assessment: A single-centre study and review of the literature. J Med Imaging Radiat Oncol. 2019;63(4):446-53.

2. Pinto CA, Marcella S, August DA, et al. Cardiopulmonary bypass has a modest association with cancer progression: a retrospective cohort study. BMC Cancer. 2013;13:519

3. Fleisher LA, Fleischmann KE, Auerbach AD, et al. 2014 ACC/AHA guideline on perioperative cardiovascular evaluation and management of patients undergoing noncardiac surgery: a report of the American College of
Cardiology/American Heart Association Task Force on practice guidelines. J Am Coll Cardiol. 2014;64(22):e77-137.

4. Drevet G, Maury JM, Farhat F, Tronc F. Transcatheter aortic valve implantation: a safe and efficient procedure to treat an aortic valve stenosis before lung cancer resection. Gen Thorac Cardiovasc Surg. 2019;67(3):321-3.

5. Popma JJ, Deeb GM, Yakubov SJ, et al. Transcatheter Aortic-Valve Replacement with a Self-Expanding Valve in Low-Risk Patients. N Engl J Med. 2019;380(18):1706-15.

6. Kelpis TG, Economopoulos VA, Nikoloudakis NE, Pitsis AA. Minimally invasive transapical aortic valve implantation and simultaneous major pulmonary resection. J Card Surg. 2013;28(6):660-2.

\section{Publisher's Note}

Springer Nature remains neutral with regard to jurisdictional claims in published maps and institutional affiliations.
Ready to submit your research? Choose BMC and benefit from:

- fast, convenient online submission

- thorough peer review by experienced researchers in your field

- rapid publication on acceptance

- support for research data, including large and complex data types

- gold Open Access which fosters wider collaboration and increased citations

- maximum visibility for your research: over $100 \mathrm{M}$ website views per year

At BMC, research is always in progress.

Learn more biomedcentral.com/submissions 